\title{
Tumor necrosis factor alpha mediates neuromuscular synapse elimination
}

\author{
Xiu-Qing Fu', Jian Peng ${ }^{1,2,3}$, Ai-Hua Wang ${ }^{1}$ and Zhen-Ge Luo (1)
}

\begin{abstract}
During the development of mammalian neuromuscular junction (NMJ), the original supernumerary axon inputs are gradually eliminated, finally leaving each muscle fiber innervated by a single axon terminal. However, the molecular cues that mediate the elimination of redundant axon inputs remain unclear. Here we show that tumor necrosis factor-a (TNFa) expressed in postsynaptic muscle cells plays an important role in presynaptic axonal elimination at the NMJ. We found that intramuscular injection of TNFa into the levator auris longus (LAL) muscles caused disassociation of presynaptic nerve terminals from the postsynaptic acetylcholine receptor (AChR) clusters. By contrast, genetic ablation of TNFa globally or specifically in skeletal muscle cells, but not in motoneurons or Schwann cells, delayed the synaptic elimination. Moreover, ablation of TNFa in muscle cells attenuated the tendency of activity-dependent competition in a motoneuron-muscle coculture system. These results suggest a role of postsynaptic TNFa in the elimination of redundant synaptic inputs.
\end{abstract}

\section{Introduction}

Developmental synapse elimination during early postnatal life occurs widely in the central and peripheral nervous system, and is crucial for the formation of functional neural circuits $^{1-4}$. This process is activity-dependent: inputs with relatively higher activity stabilized and inputs with lower activity gradually eliminated ${ }^{5-7}$.

The vertebrate neuromuscular junction (NMJ), a chemical synapse formed between the axon terminal of a motoneuron and a muscle fiber, has been a classical model in the study of synapse formation, elimination, and refinement ${ }^{8-11}$. At birth, each muscle fiber receives multiple innervations from spinal motoneurons. However, redundant inputs are gradually eliminated, leading to the singly innervated muscle cell within 2 weeks ${ }^{12-15}$. The competition among nerve terminals from different motoneurons is influenced by activity patterns and the relative efficacy of presynaptic inputs ${ }^{5,6,16,17}$. Recently,

\footnotetext{
Correspondence: Zhen-Ge Luo (luozhg@shanghaitech.edu.cn)

${ }^{1}$ School of Life Science and Technology, ShanghaiTech University, Shanghai 201210, China

${ }^{2}$ State Key Laboratory of Neuroscience, Center for Excellence in Brain Science and Intelligence Technology, Institute of Neuroscience, Chinese Academy of Sciences, Shanghai 200031, China

Full list of author information is available at the end of the article.
}

some retrograde factors, such as $\mathrm{BDNF} /$ proBDNF or Sama3A/Sama7A, expressed by postsynaptic cells are found to mediate presynaptic axonal elimination ${ }^{15,18-22}$. In addition, class I major histocompatibility complex (MHCI) has been reported to be involved in developmental synapse elimination at the $\mathrm{NM}^{23,24}$. Nevertheless, the molecular and cellular mechanisms regulating the competitions among nerve terminals on one single muscle fiber remain largely unknown.

Tumor necrosis factor- $\alpha$ (TNF $\alpha)$ is a pro-inflammatory cytokine acting as either a membrane-integrated ligand $(\mathrm{mTNF} \alpha)$ or a soluble ligand (sTNF $\alpha)$ after cleavage of mTNF $\alpha$ by the metalloprotease TNF- $\alpha$ converting enzyme $^{25-27}$. TNF $\alpha$ exerts biological functions via interaction with its cognate membrane receptor TNFo receptor type 1 (TNFR1) or TNFo receptor type 2 (TNFR2) $)^{27-30}$. mTNF is able to stimulate both receptors, whereas sTNF mainly acts on TNFR1 but not on TNFR2 despite highaffinity binding ${ }^{30}$. In the nervous system, TNF $\alpha$ is involved in various types of brain injury or neurodegeneration $^{31-33}$. Moreover, previous studies have shown that glial TNF $\alpha$ regulates synaptic strength and mediates synaptic scaling by modulating transmitter release or postsynaptic receptor trafficking in cultured hippocampus 
neuron $^{34-37}$. At the Drosophila NMJ, downregulation of TNF signaling attenuated NMJ degeneration mediated by disruption of neuronal skeleton protein spectrin/ ankyrin $^{38}$. Notably, several TNF members, including TNFo, LIGHT, and RANKL, inhibit neurite outgrowth and branching of cultured hippocampal neurons ${ }^{39-41}$. These studies indicate that TNFa is a possible candidate in neural refinement during early postnatal development. Thus, we try to understand the role of TNF $\alpha$ in developmental synapse elimination at the NMJ.

Here we show that TNF $\alpha$ expressed by postsynaptic muscle cells acts as a retrograde factor that induces presynaptic axonal elimination during the development of mouse neuromuscular synapses. Administration of TNF $\alpha$ into postnatal mouse levator auris longus (LAL) muscles caused separation of presynaptic nerve terminal from postsynaptic acetylcholine receptor (AChR) patches and decreased poly-innervated (PI) NMJs. However, genetic ablation of TNF $\alpha$ globally or specifically in muscle cells caused an opposite effect, leading to a significant delay of synapse elimination during the early postnatal 2 weeks. The role of TNF $\alpha$ was also determined in a motoneuron-muscle coculture system, in which activitybased synaptic competition was dampened by knockout of TNF $\alpha$ in muscle cells. Thus, TNF $\alpha$ plays an important role in synapse elimination during postnatal development.

\section{Results}

\section{Activity-dependent expression of TNFa and its receptors in developing mouse NMJs}

To investigate the role of TNF $\alpha$ in NMJ development, we first determined the expression patterns of TNF $\alpha$ in the mouse skeletal muscles and axons of motoneurons during the stage of presynaptic elimination. As shown in Fig. 1a, TNF $\alpha$ was highly expressed in soleus muscles of mice at embryonic day 18.5 (E18.5), declined after birth, bumped again at postnatal day 6 (P6), and then declined to undetectable level at the adult stage. Next, we performed immunohistochemistry for spatial localization of TNF $\alpha$ using confocal or stimulated emission depletion microscopy (STED) and found intense TNF $\alpha$ signals in muscle cells of P6 mice (Fig. 1b and Supplementary Fig. S1a). The intracellular TNF $\alpha$ puncta in muscle cells were reminiscent of vesicular TNF $\alpha$ signals during trafficking and secretion ${ }^{42,43}$ (Fig. 1b arrows and Supplementary Fig. S1a). Notably, TNF $\alpha$ signal was barely detected in terminal Schwann cells surrounding NMJs (Fig. 1b and Supplementary Fig. S1d, e). The specificity of TNF $\alpha$ and TNFR1 antibodies were confirmed by a negative signal in muscle samples from $T N F \alpha$ knockout mice and in TNFR1-knockdown cells (Supplementary Fig. S1b-f). These data suggest that TNF $\alpha$ is mainly produced by postsynaptic muscle cells at NMJs.

Synaptic refinement during postnatal neuromuscular development is activity-dependent ${ }^{5,6,16,17}$. Therefore, we determined whether the production of TNF $\alpha$ by muscle cells is activity-dependent. To test this, differentiated $\mathrm{C} 2 \mathrm{C} 12$ myotubes were stimulated with $50 \mathrm{mM} \mathrm{KCl}$ (high $\mathrm{K}^{+}$) for the indicated time (0 $\left.20 \mathrm{~min}\right)$, to induce depolarization. We found that the levels of both full-length $(28 \mathrm{kDa})$ and cleaved TNF $\alpha(17 \mathrm{kDa})$ associated with the plasma membrane increased upon $\mathrm{KCl}$ stimulation (Fig. 1c). Furthermore, the protein level of ADAM17 endopeptidase, a main TNF $\alpha$-processing enzyme that cleaves mTNFo into sTNF $\alpha$, was also increased after $\mathrm{KCl}$ stimulation (Fig. 1c, d). This result suggests that the production and processing of TNF $\alpha$ might be activitydependent. To further consolidate this conclusion, we measured the effect of light-gated cation channel Channelrhodopsin-2 (ChR2) on TNF $\alpha$ secretion from muscle cells. We found that upon pulsed blue light stimulation at a frequency mimicking physiological muscle firing for $5 \mathrm{~s}^{5}$, muscle cells expressing ChR2 tagged with mCherry exhibited a rise of calcium signals measured by GCaMP6f, which was used as a calcium probe ${ }^{44}$, and a bleach of mCherry signals (Supplementary Fig. S2a, b and Supplementary Movies S1 and 2). This result indicates that the light-gated ChR2 indeed increased activity in muscle cells (Supplementary Fig. S2a, b). Then, the same light-stimulation protocol was applied to muscle cells cotransfected with mCherry-ChR2 and TNF $\alpha$ tagged with pHluorin $^{45}$, which has a relatively low fluorescence intensity in the acidic vesicle lumen and exhibits increased fluorescence signals when fused with the plasma membrane and exposed to the outer surface with higher $\mathrm{pH}$. We analyzed the effects of activity on TNF $\alpha$ secretion, which was determined by measuring the dynamics of TNF $\alpha$-pHluorin. We found that activated muscle cells exhibited a marked increase in TNF $\alpha$-pHluorin signals, although mCherry signals were bleached (Fig. 1e, f and Supplementary Movies S3 and 4). Notably, the lightinduced increase in TNF $\alpha$-pHluorin signals was not observed in muscle cells co-expressing RFP (red fluorescent protein) and TNF $\alpha$-pHluorin (Supplementary Fig. S2c, d), and light-gating of ChR2 did not increase the cotransfected YFP (yellow fluorescent protein) signals (Supplementary Fig. S2e, f). These results indicate the specificity of ChR2 action on TNF $\alpha$-pHluorin. Next, to investigate whether TNF $\alpha$ expression is activitydependent in muscle fibers of postnatal mice, we determined the effect of neuronal firing on TNF $\alpha$ production in postsynaptic muscle cells. For this purpose, pectoralis superficial muscles from P8 mice were transfected with plasmids encoding TNFo-pHluorin together with mCherry, to mark transfected cells using electroporation, followed by sequential electrical stimulation of innervating nerve fibers (Supplementary Fig. S3a-c). As shown in Supplementary Fig. S3d, pHluorin signals remained static prior to electrical stimulation. However, upon electrical 


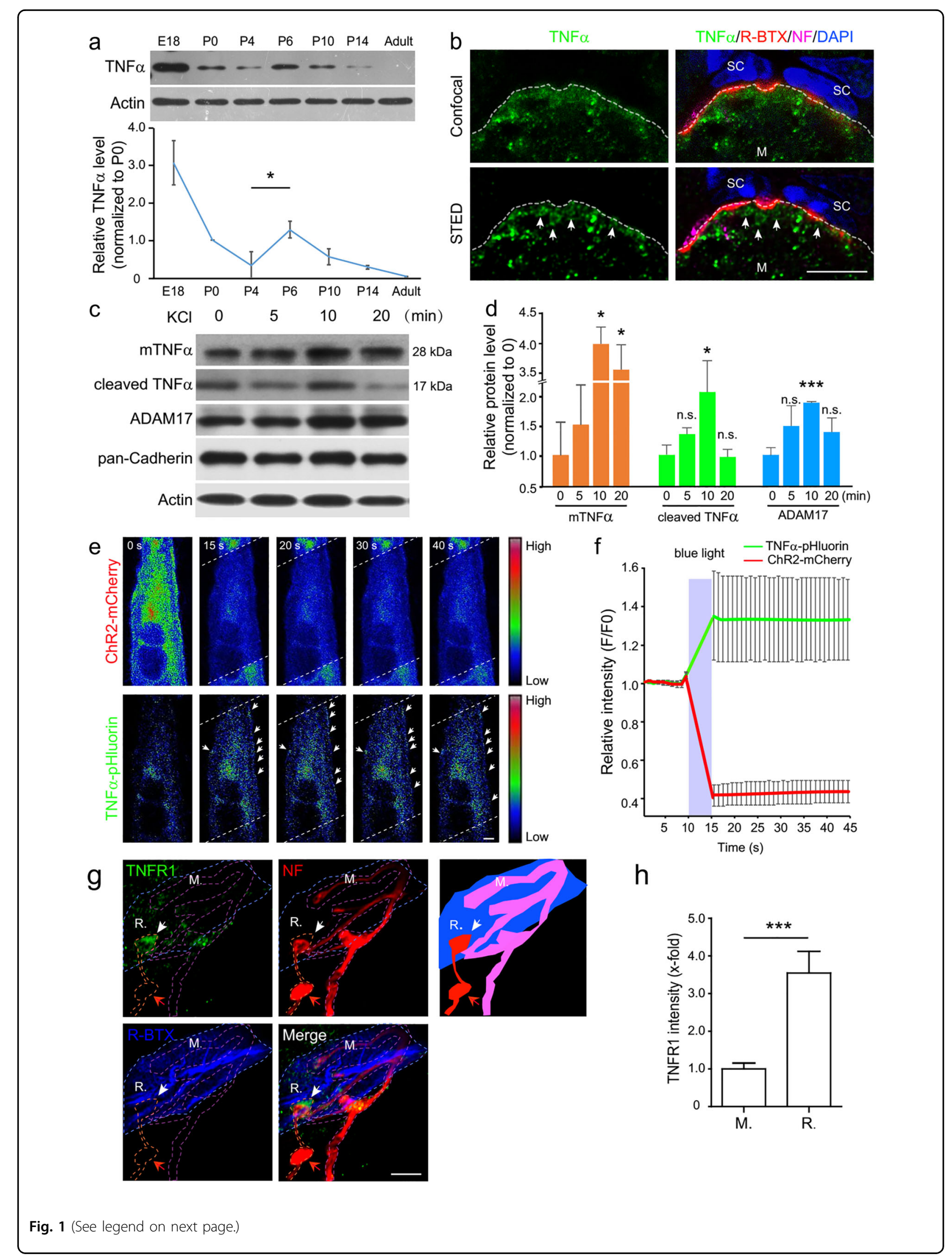


(see figure on previous page)

Fig. 1 Expression of TNFa and its receptors in neuromuscular system. a Muscle homogenates $(20 \mu \mathrm{g})$ of mice at indicated stages were subjected to immunoblotting (IB) with indicated antibodies. Relative level of TNFa protein normalized to PO was quantified from three independent experiments. Data are means \pm SEM. Mann-Whitney test was used to determine significance between P4 and P6. ${ }^{*} P<0.05$. $\mathbf{b}$ Cross-sections of P6 sternocleidomastoid muscles were stained with R-BTX (red) and antibodies against TNFa (green) and neurofilament (NF, magenta). DAPI signals (blue) show the cell nuclei of terminal SCs. Top row: confocal images, bottom row: STED images. The notable vesicular distribution of TNFa was observed with STED method in postsynaptic muscle cells (white arrows). M muscle. White dash line: muscle membrane. Scale bar: $5 \mu$ m. c, d C2C12 myotubes were treated with $50 \mathrm{mM} \mathrm{KCl}$ for the indicated time. Then the membrane fractions of treated muscle cells were subjected to IB with antibodies against TNFa, ADAM17, pan-Cadherin, or Actin. Protein levels of mTNFa, cleaved TNFa, or ADAM17 relative to pan-Cadherin were quantified and compared with 0 min (d). Data are means \pm SEM. Mann-Whitney test was used to determine significance. ${ }^{* * *} P<0.001 ;{ }^{*} P<0.05$. e, $\mathbf{f}$ C2C12 myotubes co-transfected with TNFa-pHluorin and ChR2-mCherry were stimulated with $\sim 470 \mathrm{~nm}$ laser (white dash line area) to gate the ChR2 channel to activate muscle cells, followed by time-lapse imaging. Note the decrease in mCherry signals caused by photobleaching and increase in the fluorescence intensity of TNFa-pHluorin on the membrane of myotube (arrows) (e). Normalized fluorescence intensity of TNFa-pHluorin and ChR2-mCherry was quantified (f). Data presented are mean value of 25 cells with SEM. Stimulation period is marked with gray area on the graph. Scale bar: $10 \mu \mathrm{m}$. $\mathbf{g}$ The sternocleidomastoid muscles from P10 mice were stained with R-BTX (blue) and antibodies against TNFR1 (green) and NF (red). Note the expression of TNFR1 (white arrow) in the nerve terminal with retraction bulb (red arrow). The diagram outlines areas covered by retracting (R) and maintained terminal $(M)$. Scale bar: $5 \mu \mathrm{m}$. $\mathbf{h}$ Relative intensity of TNFR1 relative to NF in retracting and maintained terminals was quantified. Data are shown as means \pm SEM of 18 NMJs from 4 mice. Mann-Whitney test was used to determine significance. ${ }^{* * *} P<0.001$.

stimulation of the nerves, innervated muscle cells exhibited subsequent increase in TNF $\alpha$-pHluorin signals (Supplementary Fig. S3e-g). Taken together, enhanced activation of muscle cells promotes secretion of TNF $\alpha$.

We also studied the expression pattern of TNF $\alpha$ receptors (TNFR1 and TNFR2) at NMJs of mice at P6 and found that TNFR1 was relatively highly expressed in nerve terminals with axon bulbs, which are hallmarks of retracting axons ${ }^{6}$, revealed by immunostaining (IS) with an antibody specifically recognizing TNFR $1^{46}$ (Fig. 1g, h; Supplementary Fig. S1f, g and Supplementary Movie S5). In agreement with a recent report ${ }^{47}$, we also found that retracting axons exhibited microtubule disassembly as reflected from reduced levels of BIII-Tubulin (Supplementary Fig. S4a). Remarkable high TNFR1 signals were observed in the terminals of axons with low levels of $\beta$ IIITubulin (Supplementary Fig. S4b, c and Supplementary Movie S6). Both TNFR1 and TNFR2 were localized in motor nerves in close opposition to the sites of postsynaptic AChRs (Supplementary Figs. S4d, S5a). Considering that competitive synapse elimination is activitydependent, we determined the relationship between neuronal activity and levels of TNF receptors in cultured motoneurons. We found that both TNFR1 and TNFR2 were expressed in cultured motoneurons and, interestingly, treatment with high $\mathrm{K}^{+}(50 \mathrm{mM} \mathrm{KCl}, 30 \mathrm{~min})$ to induce neuronal depolarization caused a decrease in the level of membrane-associated TNFR1 but an increase in TNFR2 (Supplementary Fig. S5b-d). Thus, the expression levels of TNFR1 and TNFR2 show distinct alterations related with neuronal activity.

\section{Administration of TNFa induces retraction of nerve terminals in LAL muscles}

To determine the role of TNF $\alpha$ in postnatal synapse elimination at the NMJ, we took advantage of the LAL muscle, which is suitable for intramuscular application of exogenous factors or pharmacological agents via subcutaneous injection ${ }^{48}$. Interestingly, two recent studies using LAL muscles as a model to study synapse elimination through pharmacological manipulation have led to identification of a role of proBDNF in synapse elimination via TrkB/p75 neurotrophin receptors ${ }^{21,49}$. Given the negative phenotype of BDNF knockout mice in synapse elimination ${ }^{21}$, we hypothesized the presence of other retrograde factor, which is likely to be TNF $\alpha$. To test this idea, purified TNF $\alpha$ protein was subcutaneously injected into the left LAL muscles from P3 to P13 twice daily (Fig. 2a). To examine the ultrastructure of NMJs, we did transmission electron microscopy (TEM) analysis for LAL muscles of P7 mice after treatment with TNFa or BSA (bovine serum albumin) for 4 days. As shown in Fig. 2b, LAL muscles were normally innervated by axon terminals with numerous synaptic vesicles in control mice. However, after TNF $\alpha$ treatment, the ultra-structure of axon terminals at the NMJ became abnormal with the lack of synaptic vesicles (Fig. 2b, c and Supplementary Fig. S6a). Next, we analyzed every single NMJ after drug administration for 4 days at P7. TNF $\alpha$ treatment caused a decrease of the percentage of NMJs that were innervated by $\geq 2$ axons (PI) compared with the control group (Fig. 2d, f). At P14, almost all of the postsynaptic AChR patches were innervated by a single axon terminal (single-innervated, SI) in the BSA-injected control group and only residue postsynaptic sites remained noninnervated (Fig. 2e, f). Intriguingly, TNF $\alpha$ administration caused many postsynaptic AChR-enriched sites devoid of axon occupancy and a decrease of the percentage of SI NMJs (Fig. 2e, f and Supplementary Fig. S6b). These results indicate that TNF $\alpha$ can induce the retraction of axon terminals at the mouse NMJ. 

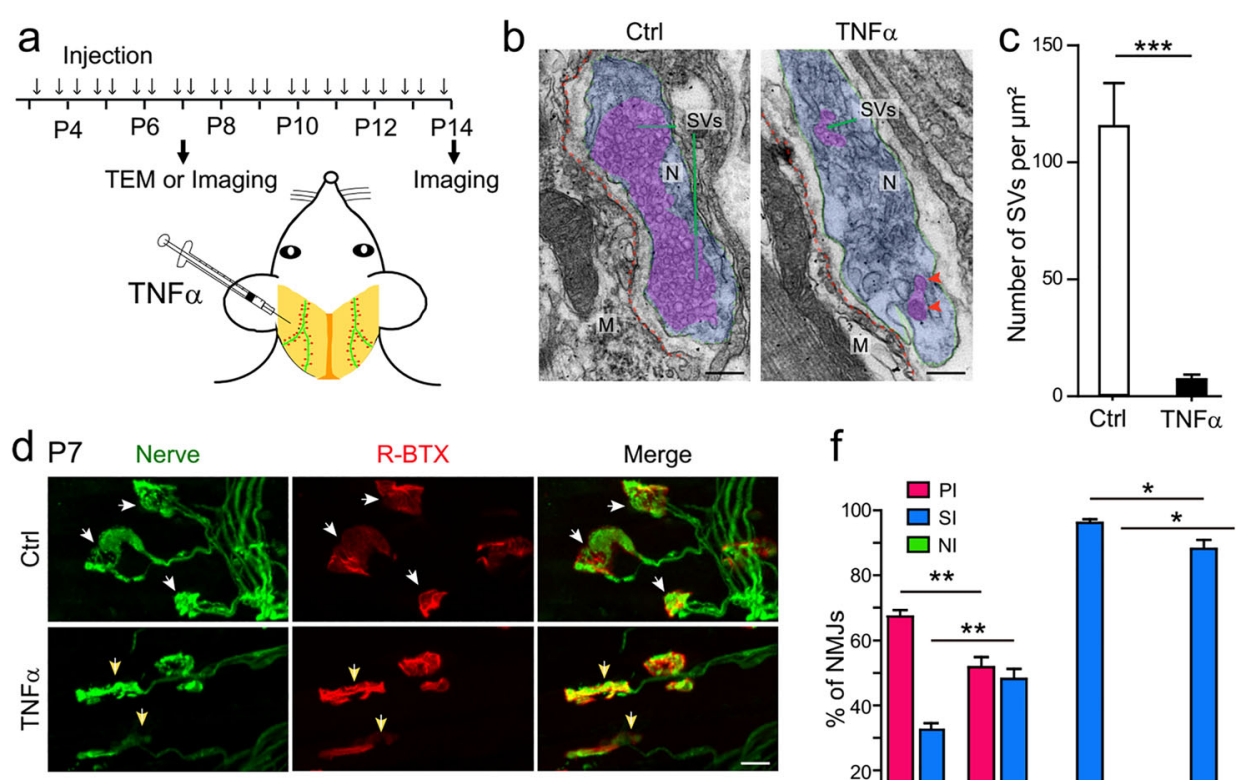

f

e
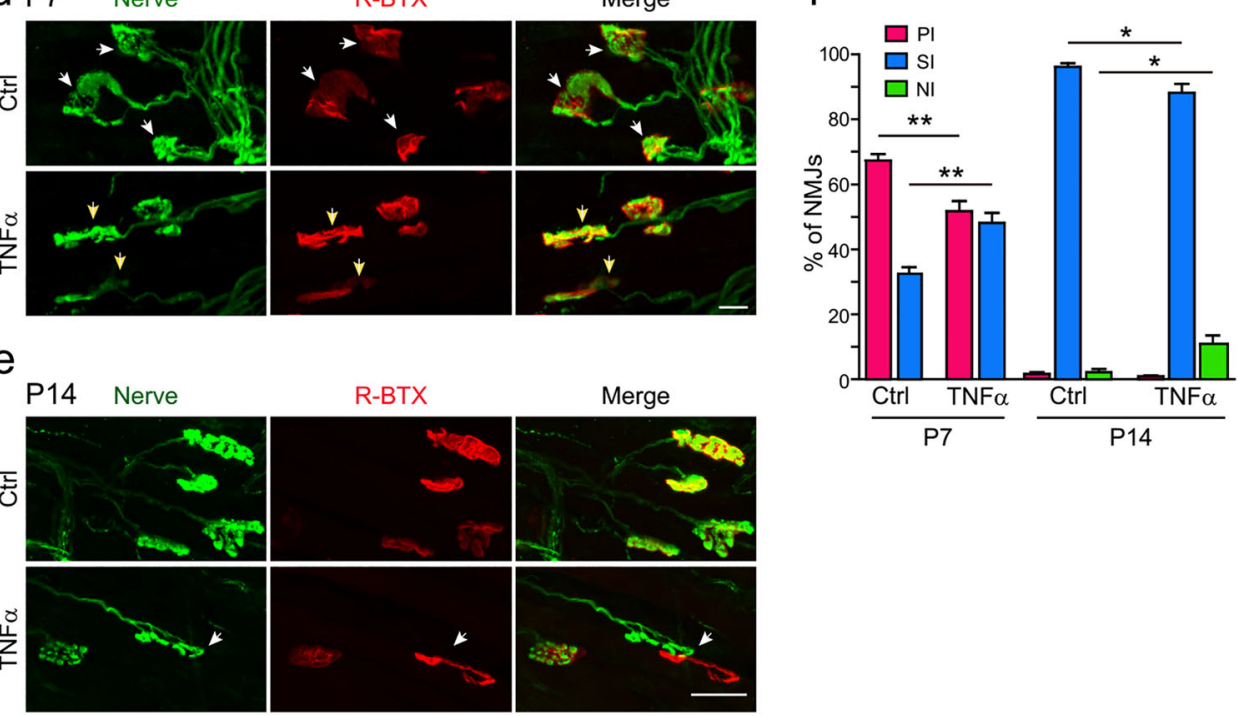

Fig. 2 TNFa treatments promote synapse elimination at postnatal NMJs. a Schematic demonstration of experimental procedures. Left: $L A L$ muscles of mice at P3 were injected with TNFa or bovine serum albumin (BSA) twice daily until P7 or P14, and then isolated for TEM or immunohistochemistry analysis. $\mathbf{b}$ EM images of NMJs of P7 mice after BSA (Ctrl) or TNFa treatment for 4 days. Blue area marks presynaptic nerve terminals with synaptic vesicles (SVs, carmine). Red dash lines delineate the postsynaptic membrane of myotubes. Note the detachment of nerve terminal from postsynaptic compartment and aberrant synaptic vesicles in TNFa-treated mice (red arrows). M: muscle, N: nerve terminal. Scale bar: $200 \mathrm{~nm}$. c The number of synaptic vesicles in TNFa treatment group was markedly reduced compared with the BSA group. Data are shown as means \pm SEM (16 NMJs from 4 mice for BSA group; 22 NMJs from 5 mice for TNFa group). Mann-Whitney test was used to determine significance. ${ }^{* * *} P<$ 0.001. d, e Drug-treated whole LAL muscles of mice at P7 (d) or P14 (e) were stained with R-BTX to label postsynaptic AChR (red) and antibodies against NF and synaptophysin to label nerve terminals (green). Note the poly-innervated NMJs (d, white arrows) in the control group and the singleinnervated NMJs (d, yellow arrows), and the disassociation of axon terminals with AChR regions in TNFa-treated group (e, white arrows). Scale bar: $20 \mu \mathrm{m}$. f Quantification of synapse elimination at mouse NMJs following drug treatment. Data are presented as means \pm SEM (P7: 644 NMJs from 6 mice of control group and 626 NMJs from 6 mice of TNFa group; P14: 676 NMJs from 4 mice of control group and 877 NMJs from 4 mice of TNFa group). Mann-Whitney test was used to determine significance. ${ }^{*} P<0.05$, ${ }^{*} P<0.01$. NI non-innervation, PI poly-innervation, SI single-innervation.

\section{Genetic ablation of TNFa delays synapse elimination at mouse NMJs}

To determine the necessity of TNF $\alpha$ in synapse elimination, we analyzed phenotypes of $T N F \alpha$ knockout $\left(T N F \alpha^{-/-}\right)$mice (Supplementary Fig. S7a, b). Similar to previous studies $^{50,51}$, the homozygous $T N F \alpha^{-/-}$mice were viable and fertile, showed no histological or morphological abnormality, and lived until adulthood. To investigate the function of TNF $\alpha$ in synapse formation, we analyzed the NMJs of mice at P0. We found that there was no difference in the number of AChR clusters between wild-type (WT) and TNF $\alpha$-deficient mice in LAL muscles (Supplementary
Fig. S7c-e), and the number of nerve arbors in diaphragm muscles (Supplementary Fig. S7f, g). Therefore, our data indicate that the absence of TNF $\alpha$ does not affect NMJ formation during an early stage of development.

Next, we examined synaptic patterns of NMJs at different postnatal stages. In line with previous observations ${ }^{13,14}$, most NMJs in the LAL muscle of WT neonatal mice were innervated by multiple axon terminals and the percentage of PI NMJs gradually decreased (Fig. 3a, b, d, e). At the end of postnatal week two, a vast majority of redundant axon inputs were gradually eliminated, leaving most NMJs SI and only minimal NMJs PI (Fig. 3a, b; $71.7 \pm 0.3 \%$ at P6; 
$7.5 \pm 1.5 \%$ at $\mathrm{P} 10 ; 2.1 \pm 0.5 \%$ at $\mathrm{P} 14 ; 0.12 \pm 0.04 \%$ at $\mathrm{P} 21$ in LAL muscles). Interestingly, the percentage of PI NMJs increased markedly in $\mathrm{TNF}^{-1-}$ mice compared with WT mice littermates in the early two postnatal weeks (Fig. 3a, b; $85.5 \pm 1.6 \%$ at $\mathrm{P} 6 ; 18.2 \pm 0.9 \%$ at $\mathrm{P} 10 ; 10.3 \pm 1.1 \%$ at $\mathrm{P} 14$; $0.3 \pm 0.1 \%$ at P21 in LAL muscles, see arrowheads). Similarly, we also found the delay of synapse elimination in sternocleidomastoid muscles in $T N F \alpha^{-/-}$mice (Fig. 3d, e). However, the area of individual NMJ marked by AChR showed no difference between WT and $T N F \alpha^{-1-}$ mice at P14 (Fig. 3c). These results suggest that TNF $\alpha$ plays an important role in presynaptic axon elimination during postnatal life at the NMJ.

Muscle-derived TNFa is important for synapse elimination

It has been hypothesized that a retrograde factor produced by postsynaptic muscle cells induced retractions of redundant axon terminals ${ }^{15,18,20}$. In addition, several studies indicated that terminal SCs participate in synapse elimination at the $\mathrm{NM}^{52,53}$. To identify the source of TNF $\alpha$ responsible for synapse elimination, we generated the $T N F \alpha^{f / f}$ mice with exon 3 and exon 4 of $T N F \alpha$ gene flanked by LoxP sites (Fig. 4a). Then, these mice were crossed with HSA-Cre, MPZ-Cre, or HB9-Cre mice to obtain mutant mice with specific ablation of $T N F \alpha$ in skeletal muscle cells, SCs, or motoneurons (Fig. 4b). Notably, TNF $\alpha$ signal was barely detectable in muscle samples from $T N F \alpha^{f f f}$; HSA-Cre mice (Fig. 4c), supporting that the expression of TNF $\alpha$ is in postsynaptic muscle cells again. Similar to global knockout mice, these conditional knockout mice had no obvious defects in synaptogenesis of NMJs at birth (data not shown). We analyzed the percentage of PI NMJs in LAL muscles at different stages and found that $T N F \alpha^{f / f}$; HSA-Cre mice exhibited a marked increase in PI NMJs compared with littermate controls at P8 and P14 (Fig. 4d, g). However, the absence of TNF $\alpha$ in SCs or motoneurons had no effect on synapse elimination (Fig. 4e-g). These results suggest that TNF $\alpha$ derived from muscle cells acts as a retrograde factor involved in postnatal synapse elimination at the NMJ.

\section{Role of TNFa signaling in activity-dependent synaptic competition in motoneuron-muscle coculture system}

During the period of synapse elimination at the NMJ, multiple afferent nerves compete for the opportunity to form synapse with the single postsynaptic muscle cell and the nerve terminals with relative higher activity are deemed to be the favored competitor ${ }^{6,7}$. To determine whether TNFa is involved in the activity-dependent competition, we developed a triplet motoneuron-muscle coculture system, in which a single myotube was innervated by two motoneurons, which expressed ChR2-
mCherry or YFP, respectively (Fig. 5a). After pulsed blue light stimulation, the behavior of innervating axons was observed using time-lapse microscope (Fig. 5b-d and Supplementary Fig. S8). We analyzed the situations with axons of both neurons intermingled on a muscle fiber, where they co-innervated an AChR patch labeled with low concentration of Rhodamine-labeled $\alpha$-bungarotoxin (RBTX) (Supplementary Fig. S8a). Remarkably, when the ChR2-expressing motoneuron (ChR2-MN) was activated by the blue light, the YFP axon innervating the same myotube gradually retracted (Fig. 5b, e; Supplementary Fig. S8a and Supplementary Movies S7, 8), usually with the appearance of retraction bulbs (Supplementary Fig. S8a and Supplementary Movie S8). However, this competition advantage did not occur in the cases where both axons co-innervating one muscle cell were either YFP or ChR2, without or with blue light stimulation (Supplementary Fig. S8b, c). These results are in agreement with the previous observation that more active inputs are favored competitors during synapse elimination $^{6}$. Interestingly, this competitive advantage of ChR2motoneurons was abrogated in the triplet cultures on muscle cells from $T N F \alpha^{-1-}$ mice (Fig. $5 \mathrm{c}$, e and Supplementary Movie S9). Thus, muscle-derived TNF $\alpha$ participates in the competitive process of synapse elimination.

\section{Role of caspase-3 in synapse elimination at NMJs}

It is known that TNFo, through TNFR1 and mitochondria-independent pathway, activates caspase- 8 and caspase- 3 cascades to induce apoptosis ${ }^{54-56}$. To determine whether caspase- 3 is also involved in the competitive process of presynaptic axon elimination, the triplets were incubated with caspase-3 inhibitor DEVD $(20 \mu \mathrm{M})$ to block caspase-3 activity. Interestingly, the competitive advantage of ChR2-MN over YFP-MN was abrogated in DEVD-treated samples (Fig. 5d, e and Supplementary Movie S10). We also found that the active caspase-3 was mainly localized in the terminals of retracting axons with low level of $\beta$ III-Tubulin (Fig. 6a, b). These data indicated that caspase- 3 is involved in synapse elimination. To investigate the role of caspase- 3 in vivo, we subcutaneously injected DEVD $(20 \mu \mathrm{M})$ into LAL muscles from P3 twice daily until P8. We found that the percentage of PI NMJs was markedly increased in DEVDtreated mice compared with control mice (Fig. 6c, d). Furthermore, caspase- $3^{+/-}$mice exhibited an increase in the percentage of PI NMJs compared with WT littermates at P9 (Fig. 6e, f). This effect was not due to the blockade on developmental motoneuron loss, because nerve branches were similar between WT and caspase $-3^{+/-}$mice (Supplementary Fig. S7h, i). These results suggest that $\mathrm{TNF} \alpha /$ caspase- 3 signaling is involved in postnatal synapse elimination during NMJ development. 

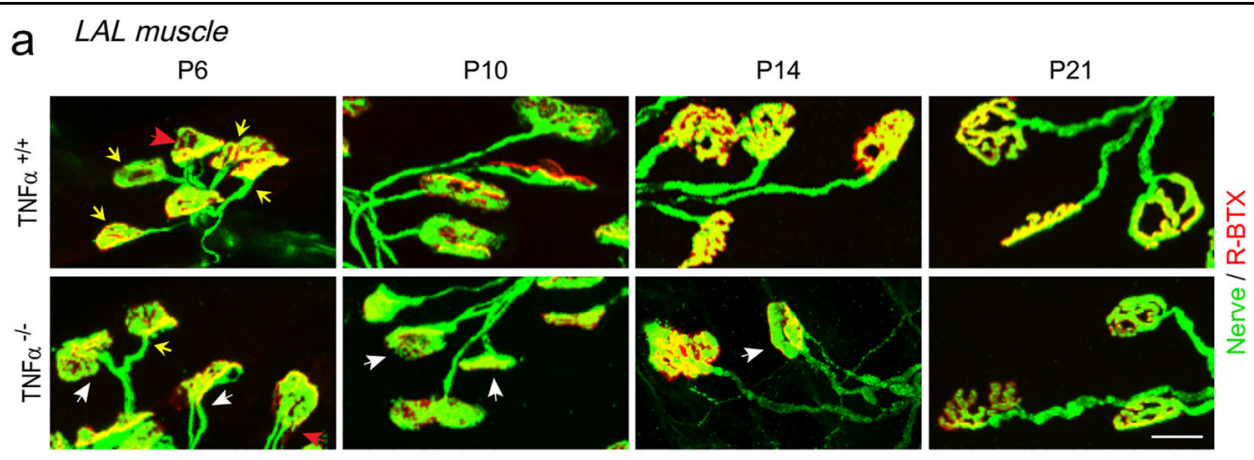

b

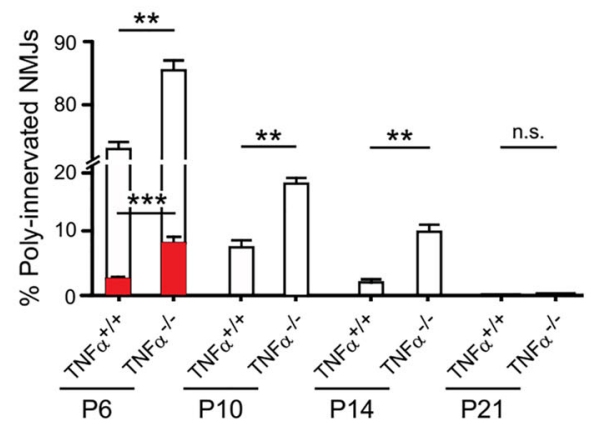

d sternocleidomastoid muscle
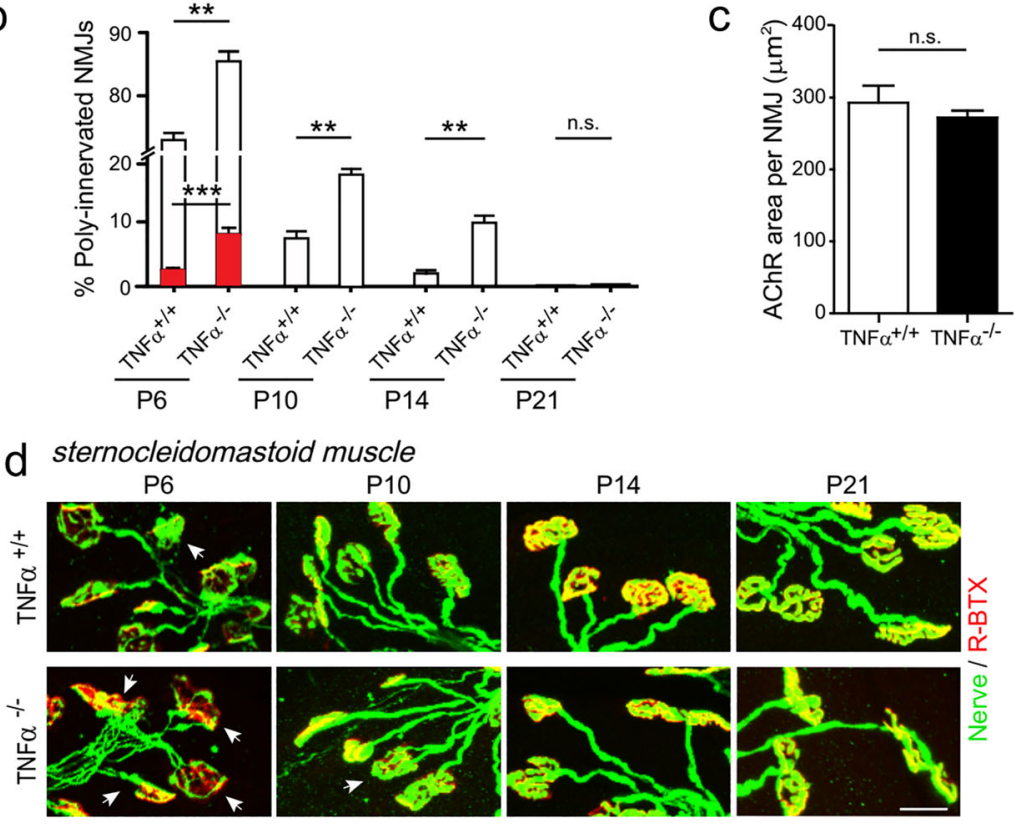

e

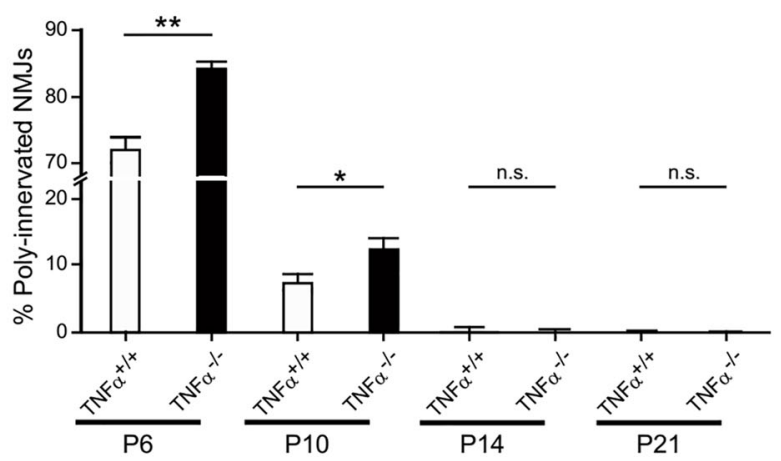

Fig. 3 Synapse elimination is delayed in TNFa-knockout mice. a LAL muscles of wild-type $\left(T N F a^{+/+}\right)$or $T N F a-k n o c k o u t ~\left(T N F a^{-1-}\right)$ mice at indicated times (P6, P10, P14, and P21) were whole-mount stained with R-BTX (red) and antibodies against NF and Syn1 (Nerve, green). Arrows indicate the NMJs innervated by single axon (yellow), two axons (white), or more than two axons (red). Scale bar: $20 \mu \mathrm{m}$. b Quantification for the percentage of NMJs innervated by $\geq 2$ axons at indicated postnatal days. Red bars represent percentage of NMJs innervated by $>2$ axons. Data are

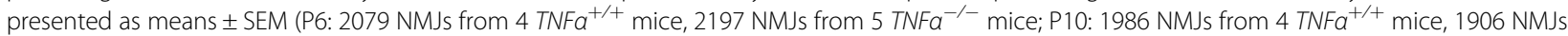
from $3 \mathrm{TNFa}^{-/-}$mice; P14: $1760 \mathrm{NMJs}$ from $5 \mathrm{TNFa}^{+/+}$mice, $1958 \mathrm{NMJs}$ from $5 \mathrm{TNFa}^{-/-}$mice; P21: $2587 \mathrm{NMJs}$ from $5 \mathrm{TNFa}^{+/+}$mice, $1897 \mathrm{NMJs}$ from $3 \mathrm{TNFa}^{-/-}$mice). Mann-Whitney test was used to determine significance. ${ }^{* *} P<0.01$, ${ }^{* *} P<0.001$, NS no significant difference. c Quantification for the average area of individual NMJ in P14 mice. Data are shown as means \pm SEM from 91 NMJs in TNFa ${ }^{+/+}$mice and $100 \mathrm{NMJs}^{-1} \mathrm{TNFa}^{-/-}$mice. Mann-Whitney test was used to determine significance. NS no significant difference. $\mathbf{d}$ Sternocleidomastoid muscles of $\mathrm{TNFa}^{+/+}$or TNFa $^{-/-}$mice at indicated time points were whole-mount stained with R-BTX (red) and antibodies against NF and Syn1 (Nerve, green). White arrows indicate the polyinnervated NMJs. Scale bar: $20 \mu \mathrm{m}$. e Quantification of the percentage of poly-innervated NMJs. Data are shown as means \pm SEM (P6: 3162 NMJs from $4 \mathrm{TNFa}^{+/+}$mice, $3514 \mathrm{NMJs}$ from $6 \mathrm{TNFa}^{-/-}$mice; P10: $4416 \mathrm{NMJs}$ from $8 \mathrm{TNFa}^{+/+}$mice, $3121 \mathrm{NMJs}$ from $5 \mathrm{TNFa}^{-/-}$mice; P14: 3859 NMJs from 6 $\mathrm{TNFa}^{+/+}$mice, $2204 \mathrm{NMJs}$ from $3 \mathrm{TNFa}^{-/-}$mice; P21: $2532 \mathrm{NMJs}$ from $5 \mathrm{TNF}^{a+/+}$ mice, $1854 \mathrm{NMJs}$ from $4 \mathrm{TNFa}^{-/-}$mice). Mann-Whitney test was used to determine significance. ${ }^{*} P<0.05,{ }^{* *} P<0.01$, NS no significant difference. 
a

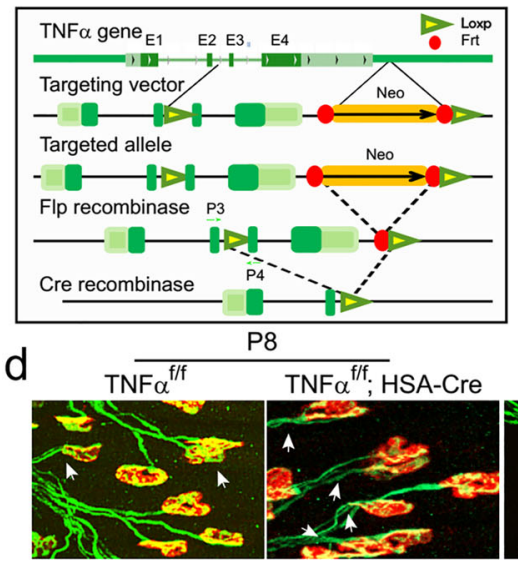

e

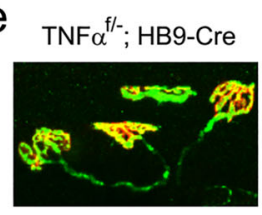

f

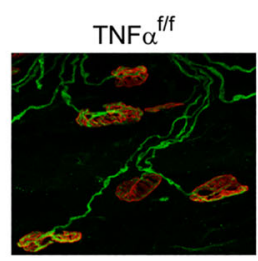

b

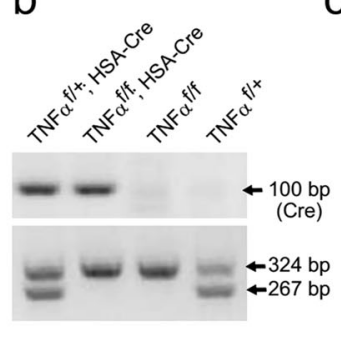

C

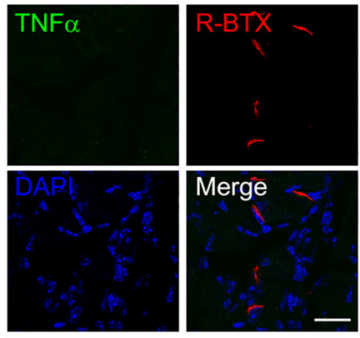

$\mathrm{P} 14$
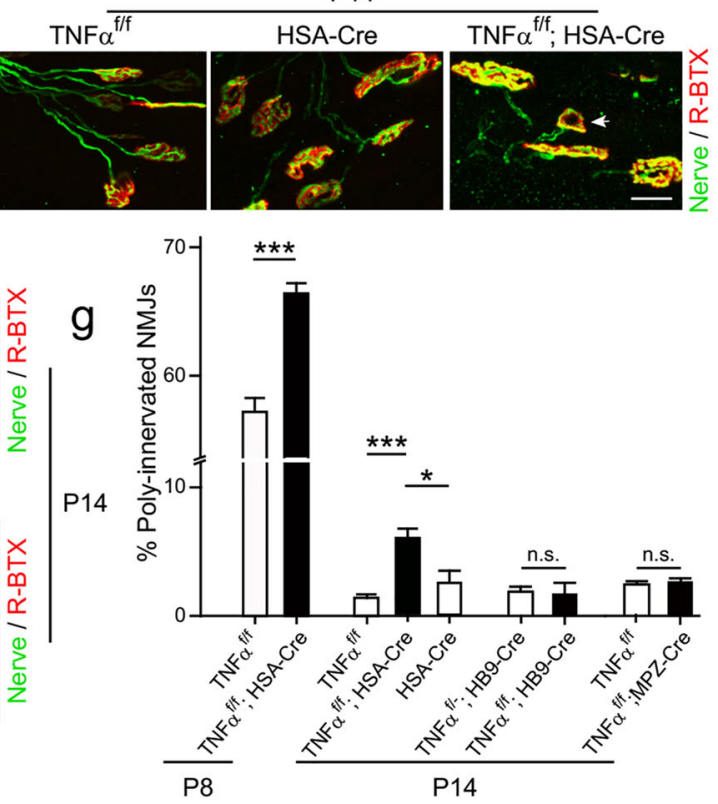

Fig. 4 Genetic ablation of TNFa in skeletal muscle cells delays synapse elimination. a Strategy for gene targeting. A pair of LoxP sites flanked exon 3 and 4 of murine TNFa gene. The Cre-LoxP and Flp-Frt systems were used to ablate TNFa gene and selection marker Neo from the murine genome, respectively. P3 and P4 indicate sites corresponding to primers used for genotyping. $\mathbf{b}$ Genotyping of conditional knockout mice using PCR method. c Absence of TNFa expression in sternocleidomastoid muscles of TNFa ${ }^{\text {fff; }}$ HSA-Cre mice at P6. Scale bar: $20 \mu \mathrm{m}$. $\mathbf{d}-\mathbf{f}$ LAL muscles of conditional knockout mice at indicated times (P8, P14) were whole-mount stained with R-BTX (red) and antibodies against NF and Syn1 (Nerve, green). Shown are example images of NMJs of mice with indicated genotypes at indicated times. White arrows indicate poly-innervated NMJs (d). Scale bars: $20 \mu \mathrm{m}$. g Quantification for the percentage of poly-innervated NMJs. Data are shown as means \pm SEM (P8, 1877 NMJs from 4 TNFa ${ }^{f / f}$ mice, 2002 NMJs from 4 TNFa $^{f / f}$; HSA-Cre mice; P14, 1036 NMJs from 6 TNFa f/f mice, 3708 NMJs from 8 TNFa ${ }^{f / f}$; HSA-Cre mice, 1372 NMJs from 3 HSA-Cre mice, $1636 \mathrm{NMJ}$ from $3 \mathrm{TNFa}^{\mathrm{f} /-}$; HB9-Cre mice, $636 \mathrm{NMJs}$ from $3 \mathrm{TNFa}^{\mathrm{f} / \text {; }}$; HB9-Cre mice, $1707 \mathrm{NMJs}$ from 3 TNFa ${ }^{\mathrm{f} / \mathrm{f}}$ mice, $3708 \mathrm{NMJs}$ from 3 TNFa ${ }^{\mathrm{f} / \text {; }}$; MPZCre mice). Mann-Whitney test was used to determine significance. ${ }^{*} P<0.05$, ${ }^{* *} P<0.001$, NS no significant difference.

\section{Discussion}

Synapse elimination is an important process for maturation and refinement of neural circuits during the development of the nervous system ${ }^{2,8}$. In rodents, more than two axon terminals compete for the same postsynaptic muscle fiber but most of them are destined for the elimination only leaving the muscle fiber mono-innervated ${ }^{14,57}$. The molecular mechanism that regulates this synapse elimination remains poorly understood. The results presented in this work suggest a role of inflammatory factor TNFo in mediating developmental synapse elimination at the NMJ (see Fig. 7 for the model). This conclusion is supported by several lines of evidences: first, the expression patterns of TNF $\alpha$ in skeletal muscles coincided with the period of inputs pruning; second, the expression of TNF $\alpha$ in muscle cells and receptors in motoneurons are activity-dependent; third, ectopic TNF $\alpha$ injection induced removal of presynaptic terminals; finally, and most importantly, genetic ablation of TNF $\alpha$, in particular in the muscle cells, postponed the postnatal elimination of neuromuscular synapses.

\section{TNFa as a retrograde factor mediating presynaptic elimination during NMJ development}

Synapse elimination at NMJs or axonal pruning in retino-geniculate refinement during early postnatal development have been suggested to be mediated by retrograde factors produced by postsynaptic cell ${ }^{15,20,21,58}$. It has been hypothesized that synapse elimination or 
a

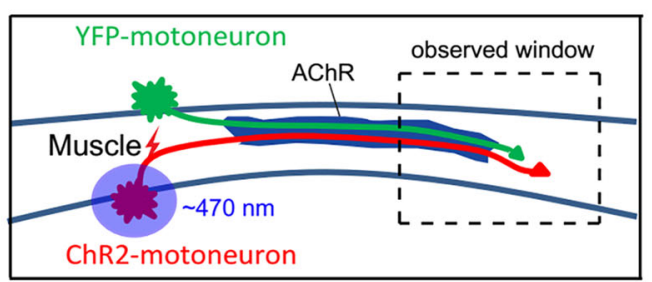

b

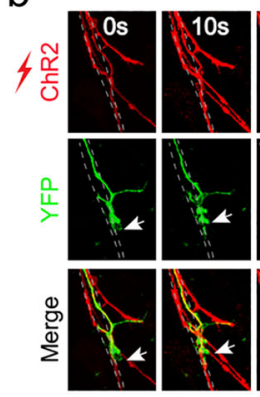

e

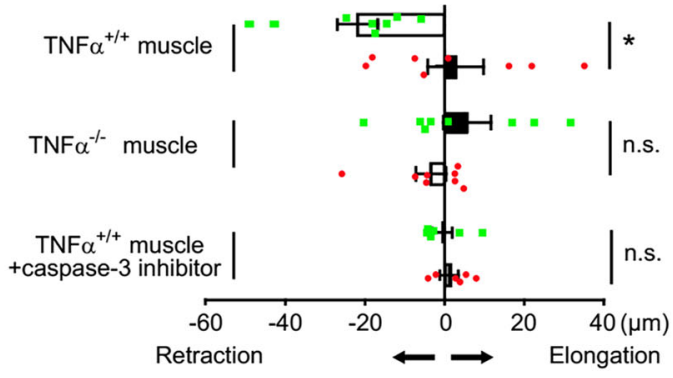

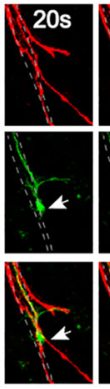
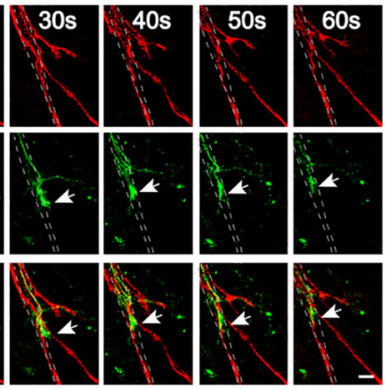

- Unstimulated neuron (YFP-MN)

- Stimulated neuron (ChR2-MN)
C TNF $\alpha-$ - muscle

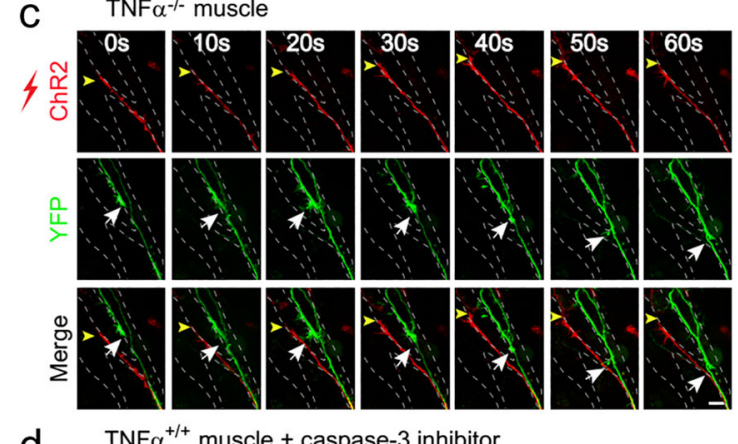

d $\mathrm{TNF}^{+/+}$muscle + caspase-3 inhibitor

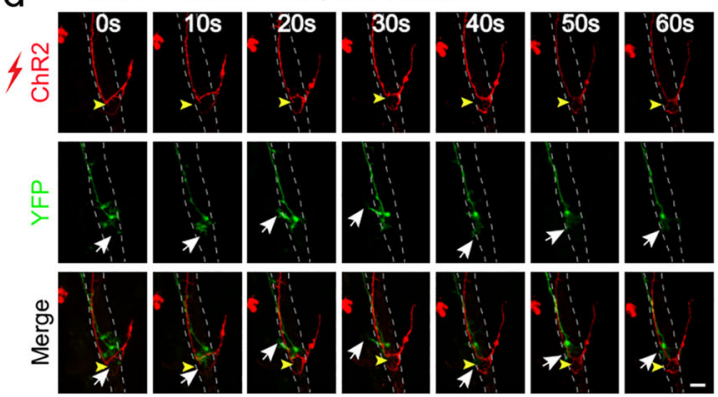

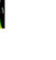


a
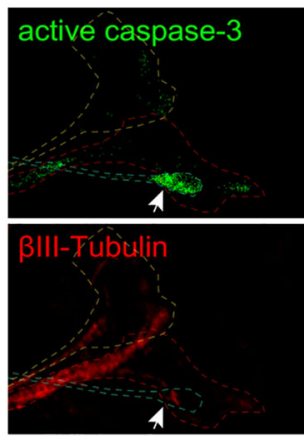

C

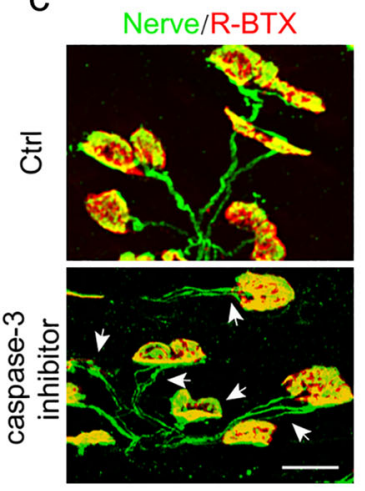

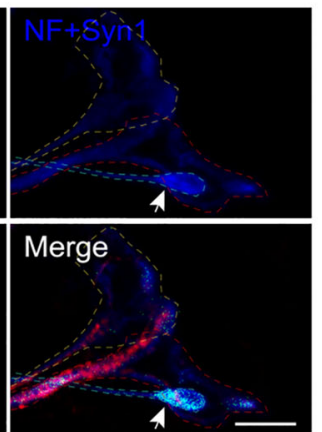

d

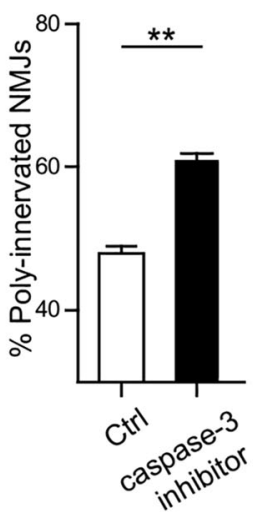

e

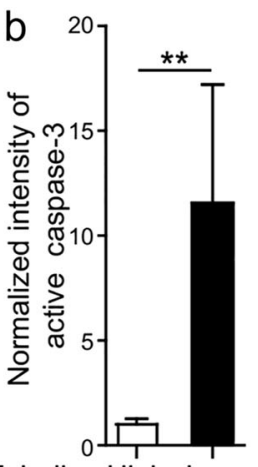

Blll-Tubulin High Low

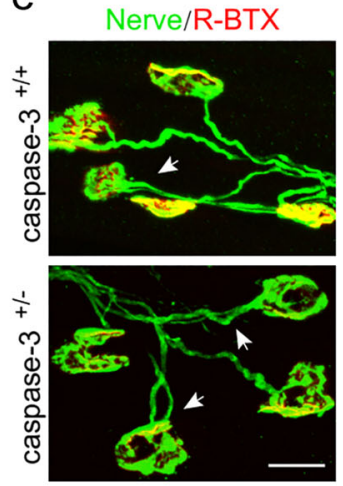

f

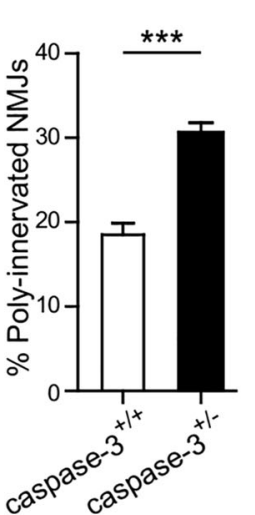

Fig. 6 Caspase-3 is involved in NMJ synapse elimination. a The pectoralis superficial muscles from mice at P10 were incubated with FITC-DEVDfmk for $1 \mathrm{~h}$ to probe active caspase-3 (green) and co-stained with indicated antibodies.Note the high level of active caspase-3 (arrows) in the retracting nerve terminal, which has lower level of $\beta$ III-Tubulin. Scale bar: $5 \mu \mathrm{m}$. b Quantification for normalized intensity of active caspase-3 relative to the terminal volume measured by NF and Syn 1 signals. Data are shown as means \pm SEM from ten NMJs in each group. Mann-Whitney test was used to determine significance. ${ }^{*} P<0.01$. c Caspase-3 inhibitor DEVD $(20 \mu \mathrm{M})$ or control vehicle DMSO was injected into LAL muscles twice daily from P3 and examined at P8 by staining with R-BTX (red) and antibodies against NF and Syn1 (Nerve, green). Note the poly-innervated NMJs (arrows) in representative images. Scale bar: $20 \mu \mathrm{m}$. d Quantification for the percentage of poly-innervated NMJs. Data are shown as means \pm SEM (control: $n=$ 5349 NMJs from 6 mice; caspase-3 inhibitor: $n=6132$ NMJs from 7 mice). Mann-Whitney test was used to determine significance. ${ }^{* *} P<0.01$. e LAL muscles from wild-type or caspase-3+/- mice at P9 were stained with R-BTX (red) and antibodies against NF and Syn1 (Nerve, green). White arrows indicate the poly-innervated NMJs. Scale bar: $20 \mu \mathrm{m}$. $\mathbf{f}$ Quantification for the percentage of poly-innervated NMJs. Data are shown as means \pm SEM (caspase- $3^{+/+}: n=4240$ NMJs from 4 mice; caspase- $3^{+/-}: n=4635$ NMJs from 4 mice). Mann-Whitney test was used to determine significance. ${ }^{* * *} P$ $<0.001$.

that TNF $\alpha$ acts as a retrograde factor regulating developmental synapse elimination at the NMJ. During the period of postnatal synapse elimination, TNFo is mainly produced by postsynaptic muscle cells. Considering that the developmental NMJ elimination is activitydependent ${ }^{5,6,16,17}$, the regulation of TNF $\alpha$ expression by activity of muscle cells (Fig. 1c-f) makes it an ideal candidate as a "punishment" factor. In line with this hypothesis, genetic ablation of TNF $\alpha$ gene in muscle cells, but not in SCs or motoneurons, postponed the postnatal synapse elimination (Fig. 4). Although we failed to observe the presence and the role of TNFa in terminal SCs, this study does not exclude the involvement of SCs in synapse elimination through the expression of other factors as reported in previous studies ${ }^{52,53,60}$. Alternatively, it remains possible that TNF $\alpha$ mediates presynaptic elimination through SCs that may also express TNF receptors.

\section{Mechanism of TNFa presynaptic elimination during NMJ development}

How does the selective elimination of inappropriate synaptic connections happen? Interestingly, several classes of immune molecules, including $\mathrm{C} 1 \mathrm{q}$, the initiating protein in the classical complement cascade, and $\mathrm{MHCI}$, play important roles in developmental synapse elimination ${ }^{61-64}$. Although synapse elimination at the NMJ occurred normally in mice deficient for pivotal protein of the complement cascade $\mathrm{C} 3^{61}$, MHCI appeared to be involved ${ }^{23}$. In addition, glutamatergic transmission via $N$-methyl-Daspartate (NMDA) receptors seemed to be involved in the 


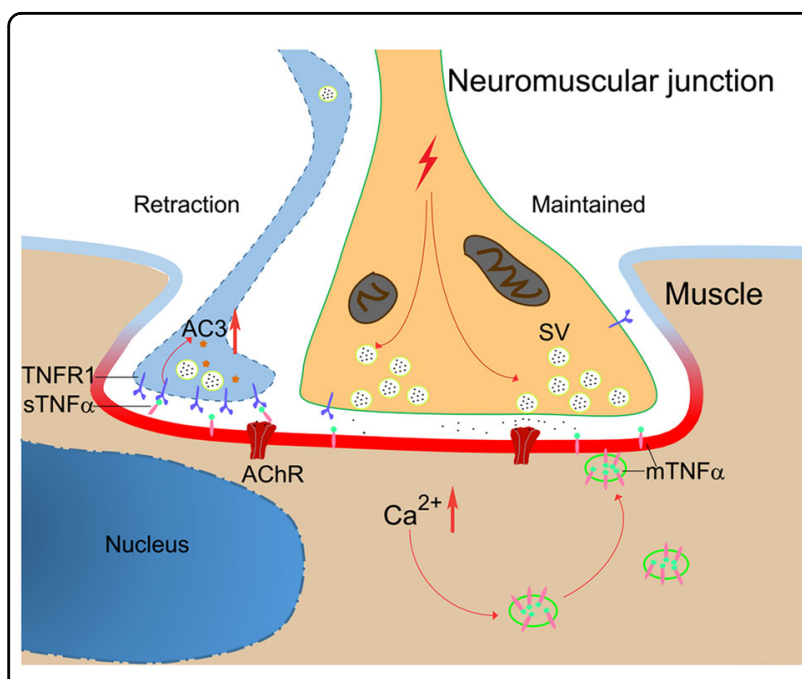

Fig. 7 Proposed model of TNFa action in synapse elimination at the NMJ. Synaptic activity induces TNFa expression from postsynaptic muscle cells, which in turn promotes pruning of nerve terminals with relatively low activity, high expression of TNFR1, and the activation of caspase-3. AC3, active caspase-3.

removal of excess innervation at the end plate ${ }^{65}$. It would be of interest to determine the interplay between NMDA and TNF $\alpha$ signaling, e.g., whether NMDA-induced $\mathrm{Ca}^{2+}$ influx regulates TNF $\alpha$ expression or processing from postsynaptic muscle cells, and whether TNF $\alpha$ regulates membrane localization of glutamate receptors. Indeed, it has been shown that TNF $\alpha$ participates in synaptic scaling via upregulating the surface level of AMPAR ${ }^{36}$.

How does TNF $\alpha$ select which inputs to be "punished"? TNF $\alpha$ signal is transduced via two distinct receptors, TNFR1 and TNFR2, which mediate different downstream signaling pathways and control the life and death balance of cells ${ }^{29,66}$. It is known that TNFR1, through the cytoplasmic domain, recruits several adaptor protein, including TNFR1-associated death domain protein, receptorinteracting protein 1 , and TNF-receptor-associated factor 2 , and activates caspase- 8 and caspase- 3 cascades to mediate mitochondria-independent apoptosis ${ }^{54-56}$. Of note, several studies have identified non-apoptotic roles of caspase-3 in the elimination of postsynaptic structures $^{67,68}$. The relatively high expression of TNFR1 and active caspase- 3 in retracting axons (Figs. $1 \mathrm{~g}$ and 6a), and reverse correlation between the expression level of TNFR1 with neuronal activity (Supplementary Fig. S5b, c) suggest that different state of TNFR1/caspase-3 signaling may determine the competition outcome. In line with this notion, inhibition of caspase- 3 interfered with synapse elimination in triplet culture system and in vivo (Figs. 5d, e and $6 \mathrm{c}-\mathrm{f})$. In contrast to TNFR1, the expression of TNFR2 in motoneurons was enhanced by neuronal activity (Supplementary Fig. S5b, c). It remains to be investigated whether the differential expression patterns of TNF receptors, different responses to membranebound or soluble form of TNFa ligand, and complex downstream signaling network discriminate initial axonal inputs encoding for maintenance or retraction. It has been shown that branch-specific disassembly of axonal microtubule is involved in developmental synapse elimination at the $\mathrm{NM}^{47}$. It would be of interest to establish the link between TNF $\alpha$ signaling and axonal microtubule stability.

In conclusion, our study uncovers an important role of TNFa in regulating synapse elimination at NMJs. Nevertheless, this study does not exclude the involvement of other factors expressed in muscle cells, SCs, or neurons in synapse elimination. In addition to the reported role in regulating synaptic scaling ${ }^{36}$, TNF $\alpha$ may also participate in structural synaptic plasticity in the central nervous system, such as the retino-geniculate refinement ${ }^{34,69}$.

\section{Materials and methods Mice}

Animal experiments were conducted according to the guidelines of Animal Use and Care Committees of Institute of Neuroscience, Chinese Academy of Sciences. $T N F \alpha$-knockout mice (JAX003008), MPZ-Cre transgenic mice (JAX017928), HB9-Cre transgenic mice (JAX00600), and caspase-3-knockout mice (JAX 006233) were from Jackson Laboratory. The HSA-Cre mice were introduced in previous studies ${ }^{70-72}$. The $T N F^{\text {floxed/floxed }}\left(T N F^{f / f}\right)$ mice with loxP sites flanking exons 3 and 4 of $T N F \alpha$ gene were generated by Biocytogen Company (Beijing, China). The following primers were used for the genotyping of conditional knockout mice: Cre, 5'-GCGGTCTGGCAGTAAAAACTATC-3' (P1) and 5'-GTGAAACAGCATTG CTGTCACTT-3' (P2); TNF $\alpha, 5^{\prime}$-CTACACAGAAGTTC CCAAATGGC-3' (P3), and 5'-GTCACTCGAATTTTG AGAAGATGATCC-3' (P4). All mice analyzed were in the $C 57 B L / 6 \mathrm{~J}$ background.

\section{Reagents and antibodies}

Antibodies were from the following: Abcam (TNFoab1793 for western blotting, WB; TNFR2-ab7369 for WB and immunostaining, IS), Novus (TNF $\alpha$-NBP1-19532 for IS), Cell Signaling (Neurofilament-L-NF-2837s for IS, Synapsin-1-(Syn1)-5297s for IS), Invitrogen (Synaptophysin(SYP)-18-0130 for IS), Chemicon (Actin-MAB1501 for WB), Kangcheng Biotechnology (GAPDH-kc-5G4 for WB), and Sigma (pan-Cadherin-C1821 for WB). DAPI (4',6-diamidino-2-phenylindole) was from Beyotime. The secondary antibodies used in immunostaining were from Invitrogen. Horserdish peroxidase-conjugated secondary antibodies were from Millipore. Recombinant agrin and goat-antiTNFR1 (AF-425-PB for IS) were from R\&D. R-BTX was from Invitrogen. Caspase-3 inhibitor Ac-DEVD-cmk (shorted as DEVD, 218750) and caspase-3 activity detection probe (FITC-DEVD-FMK, JA5700) were from Merk/ 
Calbiochen. pTNF $\alpha$-pHluorin, pCAGGS-RFP, and pCAGGS-eYFP were constructed in this work. pCAGGSChR2-mCherry and pCAGGS-mCherry were gifts from Dr Zilong Qiu. pGP-CMV-GCaMP6f was from GENIE Project (Addgene plasmid \#40755).

\section{Total and membrane protein extraction}

The limb muscle of mice were homogenized in cold lysis buffer containing $50 \mathrm{mM}$ Tris- $\mathrm{HCl}, \mathrm{pH} 7.5,150 \mathrm{mM} \mathrm{NaCl}$, $1 \%$ Nonidet P-40, $0.5 \%$ sodium deoxycholate, and protease inhibitors Cocktail set III (539134, Merk/Millipore). Membrane proteins of $\mathrm{C} 2 \mathrm{C} 12$ myotubes or cultured primary motoneurons were prepared by using plasma membrane protein extraction kit (k268-50, Biovision) and subjected to immunoblotting experiments using indicated antibodies.

\section{Muscle cell culture, transfection, and optogenetic manipulation}

C2C12 muscle cells or primary muscle cells from P0 mice were cultured in Dulbecco's modified Eagle's medium (DMEM) containing 20\% fetal bovine serum and induced for differentiation in DMEM medium containing 3\% horse serum. C2C12 myoblasts were transfected with plasmids (TNFo-pHluorin plus ChR2-mCherry, RFP plus TNFopHluorin, YFP plus ChR2-mCherry, or ChR2-mCherry plus GCaMP6f) using Lipofectamine ${ }^{\circledast} 2000$ (11668-019, ThermoFisher), followed by differentiation into myotubes and live-imaging analysis under Nikon FN1 laser scanning confocal microscope (NIR Apo 40x DIC Water N.A. 0.8). For triple-color imaging, excitation laser of $488 \mathrm{~nm}$ (Emission spectrum-Em: $500-550 \mathrm{~nm}$ ), $543 \mathrm{~nm}$ (Em: $570-620 \mathrm{~nm}$ ), and $640 \mathrm{~nm}$ (Em: 663-738 nm) were used. ChR2-expressed myotube were photo-activated with $\sim 470 \mathrm{~nm}$ laser $(2 \mathrm{~Hz}$, $5 \mathrm{~ms}$ per pulse, 10 pulses, $60 \mathrm{~s}$ interval), followed by imaging analysis for fluorescence dynamics of GCaMP6f or TNF $\alpha$ pHluorin (excitation $488 \mathrm{~nm}$; EM: $500-550 \mathrm{~nm}$ ) by recording every picture per second. Post-acquisition images were processed with Rainbow RGB of Fiji software to obtain the pseudo-color images.

\section{Transmission electron microscopy analysis}

The LAL muscles, dissected from P7 mice after drug treatment, were fixed on ice overnight with $2.5 \%$ glutaraldehyde and $4 \%$ paraformaldehyde (PFA) in about $1 \mathrm{~cm} \times 1 \mathrm{~cm}$ size. Then the muscles were embedded using sandwich method (muscles were embedded between two sheets of glass slides) and treated as described in our recent study ${ }^{73}$. We prepared the muscle slice at $50 \sim$ $70 \mathrm{~nm}$ thickness using LEICA EM UC7 and observed the images of NMJs with JEOL JEM-1230 TEM.

\section{TNFa treatment of LAL muscles}

Purified TNFa proteins (10 20 ng) in saline containing $0.1 \% \mathrm{BSA}(\mathrm{v} / \mathrm{v})$ were injected twice daily subcutaneously to the left LAL muscle of neonatal mice starting from P3. At P7 or P14, the whole left LAL muscles were isolated and subjected to TEM or immunostaining analysis. The left LAL muscles from mice injected with $0.1 \%$ BSA were used as control.

\section{Activity-dependent synaptic competition and time-lapse imaging}

Motoneurons isolated from E13.5 rat spinal cord were transfected with ChR2-mCherry or YFP plasmids separately by in vitro electroporation using the Amaxa Nucleofector device, then mixed $\left(1 \sim 4 \times 10^{4}\right.$ cells $\left./ \mathrm{mL}\right)$ and plated on differentiated primary muscle cells, and cultured for $24 \mathrm{~h}$ according to the protocol introduced previously ${ }^{68,74,75}$. The somas of ChR2-expressing motoneurons were stimulated with pulsed blue light $(\sim 470 \mathrm{~nm}, 2 \mathrm{~Hz}, 5 \mathrm{~ms}$ per pulse, 10 pulses per trial with $60 \mathrm{~s}$ interval), followed immediately by time-lapse imaging. For dual-color imaging, excitation laser of $473 \mathrm{~nm}$ (Em: $490-560 \mathrm{~nm})$ and $543 \mathrm{~nm} \quad(\mathrm{Em}$ : $570-620 \mathrm{~nm}$ ) were employed. During stimulation, phasecontrast images and fluorescent images were recorded every $10 \mathrm{~min}$ with Z-series stack at $1.0 \mu \mathrm{m}$ interval, using Olympus FV1000 confocal microscope with a $\times 40$ water objective (Olympus). The morphology of motoneuron was reconstructed from images containing several $Z$-stacks (5 10 stacks) and projected to two dimensions (2D) with maximum intensity.

\section{Immunohistochemistry, confocal microscopy image analysis, and statistics}

LAL muscles were dissected after fixation with 4\% PFA for $12 \mathrm{~h}$ at $4{ }^{\circ} \mathrm{C}$ and subjected to whole-mount staining with R-BTX and indicated antibodies following the procedure described previously ${ }^{21,76}$. The presynaptic nerve terminals were marked with antibodies against intermediate neurofilament (NF) and synaptic vesical protein synaptophysin or synapsin-1, and R-BTX to label postsynaptic AChR. Images were acquired on a NIKON A1R or $\mathrm{TiE}$ laser scanning confocal microscope with $1 \mu \mathrm{m}$ interval in each stack, reconstructed to three dimensions (3D) containing several Z-stacks (40 50 stacks) and projected to $2 \mathrm{D}$ with maximum intensity using Fiji software. Every single NMJ was observed with $Z$-stacks for better visualizing the number of innervated terminals.

To identify the subcellular localization of TNF $\alpha$ at NMJ, cross-sections of sternocleidomastoid muscles at $15 \sim 20 \mu \mathrm{m}$ thickness were subjected to staining with $\mathrm{R}$ BTX and indicated antibodies. Images were acquired on a NIKON TiE laser scanning confocal microscope or LEICA TCS SP8 STED microscopy. In addition, whole sternocleidomastoid muscle was immunostained with RBTX and antibodies against NF, BIII-Tubulin, and TNFR1. Images were acquired on a NIKON TiE laser scanning confocal microscope with $0.2 \mu \mathrm{m}$ interval in 
each stack, reconstructed to 3D containing several $Z$ stacks ( $\sim 20$ stacks), and projected to $2 \mathrm{D}$ with maximum intensity using Fiji software. Post-acquisition images were processed with Fiji, Adobe Photoshop CC 2017, and Illustrator CS5 software. Data were quantitatively analyzed using Mann-Whitney test and are shown as means \pm SEM from at least three experiments $(P \leq 0.05$ was considered as significant difference).

\section{Activity-dependent expression of TNFa in vivo}

C57BL/6 mice at P7 were anesthetized using pentobarbital sodium $(40 \mathrm{mg} / \mathrm{kg})$ during all treatments. For muscle transfection, $10 \mu \mathrm{g}$ of plasmids driving exogenous expression of TNF $\alpha$-pHluorin and mCherry were injected subcutaneously to the pectoralis superficial muscle, followed by electroporation consisting of eight square wave pulses with an amplitude of $60 \mathrm{v}$, a duration of $50 \mathrm{~ms}$, and an interval of $1 \mathrm{~s}$ (ECM830; BTX). Then, the pups were placed back into the cage of mother mice. After $24 \mathrm{~h}$, the pectoralis superficial muscle were dissected and placed in warmed ACSF buffer $(124 \mathrm{mM} \mathrm{NaCl}, 2.5 \mathrm{mM} \mathrm{KCl}, 1.2 \mathrm{mM}$ $\mathrm{NaH}_{2} \mathrm{PO}_{4}, 24 \mathrm{mM} \mathrm{NaHCO} 3,5 \mathrm{mM}$ HEPES, $12.5 \mathrm{mM}$ Glucose, $2 \mathrm{mM} \mathrm{MgSO}_{4}, 2 \mathrm{mM} \mathrm{CaCl} 2$ ). The medial pectoral nerve, which innervates the pectoralis superficial muscle, was peeled and stimulated with electrical current with an amplitude of $1 \mathrm{v}(2 \mathrm{~Hz}, 5 \mathrm{~ms}$ per pulse, 10 pulses per train with $60 \mathrm{~s}$ interval) for $5 \mathrm{~min}$ in each trial. Meanwhile, live muscles were scanned with different lasers for the excitation of green $(488 \mathrm{~nm})$ and red $(543 \mathrm{~nm})$ signals, and fluorescence signals were viewed and collected using individual filter set $(500-550 \mathrm{~nm}$ for green, $570-620 \mathrm{~nm}$ for red) under Nikon FN1 confocal microscope. For real-time observation, the multichannel signals were collected for durations of $5 \mathrm{~min}$ at an interval of $1 \mathrm{~s}$.

\section{Acknowledgements}

This study was partially supported by grants from National Natural Science Foundation of China (31490591), National Key R\&D Program of China (2017YFA0700500), the Frontier Key Project of the Chinese Academy of Sciences (QYZDJ-SSW-SMC025), and Shanghai Municipal Science and Technology Major Project (Grant Number 2018SHZDZX05). We thank Dr. Qian Hu of ION Imaging Facility for microscopic analysis, Dr. Yu Kong for EM analysis, Dr. Zi-long Qiu for providing the ChR2 construct and HB9-Cre mice, and Dr. Cheng He for providing purified TNFa protein. We thank Dr. Tong Wang for suggestions on the manuscript.

\section{Author details}

'School of Life Science and Technology, ShanghaiTech University, Shanghai 201210, China. ${ }^{2}$ State Key Laboratory of Neuroscience, Center for Excellence in Brain Science and Intelligence Technology, Institute of Neuroscience, Chinese Academy of Sciences, Shanghai 200031, China. ${ }^{3}$ University of Chinese Academy of Sciences, Beijing 100049, China

\section{Author contributions}

X.Q.F., J.P. and A.H.W. conducted the experiments. X.Q.F. and Z.G.L. designed the experiments and wrote the paper.

\section{Conflict of interest}

The authors declare that they have no conflict of interest.

\section{Publisher's note}

Springer Nature remains neutral with regard to jurisdictional claims in published maps and institutional affiliations.

Supplementary Information accompanies the paper at (https://doi.org/ 10.1038/s41421-020-0143-5).

Received: 27 August 2019 Accepted: 3 January 2020

Published online: 03 March 2020

\section{References}

1. Lichtman, J. W. \& Colman, H. Synapse elimination and indelible memory. Neuron 25, 269-278 (2000).

2. Kano, M. \& Hashimoto, K. Synapse elimination in the central nervous system. Curr. Opin. Neurobiol. 19, 154-161 (2009).

3. Feldheim, D. A. \& O'Leary, D. D. M. Visual map development: bidirectional signaling, bifunctional guidance molecules, and competition. Cold Spring Harb. Perspect. Biol. 2, a001768 (2010).

4. Hashimoto, K. \& Kano, M. Synapse elimination in the developing cerebellum Cell Mol. Life Sci. 70, 4667-4680 (2013).

5. Personius, K. E. \& Balice-Gordon, R. J. Activity-dependent editing of neuromuscular synaptic connections. Brain Res. Bull. 53, 513-522 (2000).

6. Buffelli, M. et al. Genetic evidence that relative synaptic efficacy biases the outcome of synaptic competition. Nature 424, 430-434 (2003).

7. Buffelli, M., Busetto, G., Favero, M., Cangiano, L. \& Cangiano, A. Synaptic plasticity at developing neuromuscular junctions: role of the timing of spike activity in the competing inputs. Arch. Ital. Biol. 149, 167-174 (2011).

8. Sanes, J. R. \& Lichtman, J. W. Development of the vertebrate neuromuscular junction. Annu. Rev. Neurosci. 22, 389-442 (1999).

9. Sanes, J. R. \& Lichtman, J. W. Induction, assembly, maturation and maintenance of a postsynaptic apparatus. Nat. Rev. Neurosci. 2, 791-805 (2001).

10. Wu, H., Xiong, W. C. \& Mei, L. To build a synapse: signaling pathways in neuromuscular junction assembly. Development 137, 1017-1033 (2010).

11. Li, L., Xiong, W. C. \& Mei, L. Neuromuscular junction formation, aging, and disorders. Annu. Rev. Physiol. 80, 159-188 (2018).

12. Brown, M. C., Jansen, J. K. \& Van Essen, D. Polyneuronal innervation of skeletal muscle in new-born rats and its elimination during maturation. J. Physiol. 261, 387-422 (1976).

13. Balice-Gordon, R. J., Chua, C. K., Nelson, C. C. \& Lichtman, J. W. Gradual loss of synaptic cartels precedes axon withdrawal at developing neuromuscular junctions. Neuron 11, 801-815 (1993).

14. Balice-Gordon, R. J. \& Lichtman, J. W. In vivo observations of pre- and postsynaptic changes during the transition from multiple to single innervation at developing neuromuscular junctions. J. Neurosci. 13, 834-855 (1993).

15. Nguyen, Q. T. \& Lichtman, J. W. Mechanism of synapse disassembly at the developing neuromuscular junction. Curr. Opin. Neurobiol. 6, 104-112 (1996).

16. Thompson, W. J. Activity and synapse elimination at the neuromuscularjunction. Cell Mol. Neurobiol. 5, 167-182 (1985).

17. Wyatt, R. M. \& Balice-Gordon, R. J. Activity-dependent elimination of neuromuscular synapses. J. Neurocytol. 32, 777-794 (2003).

18. Jennings, C. Developmental neurobiology. Death of a synapse. Nature $\mathbf{3 7 2}$ 498-499 (1994).

19. Uesaka, N. \& Kano, M. Presynaptic mechanisms mediating retrograde semaphorin signals for climbing fiber synapse elimination during postnatal cerebellar development. Cerebellum 17, 17-22 (2017).

20. Uesaka, N. et al. Retrograde semaphorin signaling regulates synapse elimination in the developing mouse brain. Science 344, 1020-1023 (2014).

21. Je, H. S. et al. ProBDNF and mature BDNF as punishment and reward signals for synapse elimination at mouse neuromuscular junctions. J. Neurosci. 33, 9957-9962 (2013).

22. Choo, M. et al. Retrograde BDNF to TrkB signaling promotes synapse elimination in the developing cerebellum. Nat. Commun. 8, 195 (2017).

23. Tetruashvily, M. M., McDonald, M. A., Frietze, K. K. \& Boulanger, L. M. MHC promotes developmental synapse elimination and aging-related synapse loss at the vertebrate neuromuscular junction. Brain Behav. Immun. 56, 197-208 (2016).

24. Tetruashvily, M. M., Melson, J. W., Park, J. J., Peng, X. \& Boulanger, L. M. Expression and alternative splicing of classical and nonclassical $\mathrm{MHCl}$ genes in the hippocampus and neuromuscular junction. Mol. Cell Neurosci. 72, 34-45 (2016). 
25. Black, R. A. et al. A metalloproteinase disintegrin that releases tumour-necrosis factor-alpha from cells. Nature 385, 729-733 (1997).

26. Moss, M. L. et al. Structural features and biochemical properties of TNF-alpha converting enzyme (TACE). J. Neuroimmunol. 72, 127-129 (1997).

27. Horiuchi, T., Mitoma, H., Harashima, S., Tsukamoto, H. \& Shimoda, T. Transmembrane TNF-alpha: structure, function and interaction with anti-TNF agents. Rheumatology 49, 1215-1228 (2010).

28. Baud, V. \& Karin, M. Signal transduction by tumor necrosis factor and its relatives. Trends Cell Biol. 11, 372-377 (2001).

29. Locksley, R. M., Killeen, N. \& Lenardo, M. J. The TNF and TNF receptor superfamilies: integrating mammalian biology. Cell 104, 487-501 (2001).

30. Wajant, H., Pfizenmaier, K. \& Scheurich, P. Tumor necrosis factor signaling. Cell Death Differ. 10, 45-65 (2003).

31. Allan, S. M. \& Rothwell, N. J. Cytokines and acute neurodegeneration. Nat. Rev. Neurosci. 2, 734-744 (2001)

32. McCoy, M. K. \& Tansey, M. G. TNF signaling inhibition in the CNS: implications for normal brain function and neurodegenerative disease. J. Neuroinflamm. $\mathbf{5}$, 45 (2008).

33. Glass, C. K., Saijo, K., Winner, B., Marchetto, M. C. \& Gage, F. H. Mechanisms underlying inflammation in neurodegeneration. Cell 140, 918-934 (2010).

34. Beattie, E. C. et al. Control of synaptic strength by glial TNFalpha. Science 295, 2282-2285 (2002).

35. Stellwagen, D., Beattie, E. C., Seo, J. Y. \& Malenka, R. C. Differential regulation of AMPA receptor and GABA receptor trafficking by tumor necrosis factor-alpha. J. Neurosci. 25, 3219-3228 (2005).

36. Stellwagen, D. \& Malenka, R. C. Synaptic scaling mediated by glial TNF-alpha. Nature 440, 1054-1059 (2006).

37. Pribiag, H. \& Stellwagen, D. TNF-alpha downregulates inhibitory neurotransmission through protein phosphatase 1-dependent trafficking of GABA (A) receptors. J. Neurosci. 33, 15879-15893 (2013).

38. Keller, L. C. et al. Glial-derived prodegenerative signaling in the Drosophila neuromuscular system. Neuron 72, 760-775 (2011).

39. Neumann, $\mathrm{H}$. et al. Tumor necrosis factor inhibits neurite outgrowth and branching of hippocampal neurons by a rho-dependent mechanism. J. Neurosci. 22, 854-862 (2002).

40. Gavalda, N., Gutierrez, H. \& Davies, A. M. Developmental regulation of sensory neurite growth by the tumor necrosis factor superfamily member LIGHT. J. Neurosci. 29, 1599-1607 (2009).

41. Gutierrez, H. et al. Regulation of neurite growth by tumour necrosis superfamily member RANKL. Open Biol. 3, 120150 (2013).

42. Martin-Avila, A. et al. Protein tyrosine kinase Fyn regulates TLR4-elicited responses on mast cells controlling the function of a PP2A-PKCalpha/beta signaling node leading to TNF secretion. J. Immun. 196, 5075-5088 (2016).

43. Tiwari, N. et al. VAMP-8 segregates mast cell-preformed mediator exocytosis from cytokine trafficking pathways. Blood 111, 3665-3674 (2008).

44. Chen, T. W. et al. Ultrasensitive fluorescent proteins for imaging neuronal activity. Nature 499, 295-300 (2013).

45. Miesenbock, G., De Angelis, D. A. \& Rothman, J. E. Visualizing secretion and synaptic transmission with $\mathrm{pH}$-sensitive green fluorescent proteins. Nature 394, 192-195 (1998).

46. Clark, P. R., Pober, J. S. \& Kluger, M. S. Knockdown of TNFR1 by the sense strand of an ICAM-1 siRNA: dissection of an off-target effect. Nucleic Acids Res. 36, 1081-1097 (2008)

47. Brill, M. S. et al. Branch-specific microtubule destabilization mediates axon branch loss during neuromuscular synapse elimination. Neuron 92, 845-856 (2016).

48. Angaut-Petit, D., Molgo, J., Connold, A. L. \& Faille, L. The levator auris longus muscle of the mouse: a convenient preparation for studies of short- and longterm presynaptic effects of drugs or toxins. Neurosci. Lett. 82, 83-88 (1987).

49. Garcia, N. et al. Blocking p75 (NTR) receptors alters polyinnervationz of neuromuscular synapses during development. J. Neurosci. Res. 89, 1331-1341 (2011).

50. Pasparakis, M., Alexopoulou, L., Episkopou, V. \& Kollias, G. Immune and inflammatory responses in TNF alpha-deficient mice: a critical requirement for TNF alpha in the formation of primary B cell follicles, follicular dendritic cell networks and germinal centers, and in the maturation of the humoral immune response. J. Exp. Med. 184, 1397-1411 (1996).

51. Marino, M. W. et al. Characterization of tumor necrosis factor-deficient mice. Proc. Natl Acad. Sci. USA 94, 8093-8098 (1997).
52. Smith, I. W., Mikesh, M., Lee, Y. \& Thompson, W. J. Terminal Schwann cells participate in the competition underlying neuromuscular synapse elimination. J. Neurosci. 33, 17724-17736 (2013).

53. Roche, S. L. et al. Loss of glial neurofascin155 delays developmental synapse elimination at the neuromuscular junction. J. Neurosci. 34, 12904-12918 (2014).

54. Ashkenazi, A. \& Dixit, V. M. Death receptors: signaling and modulation. Science 281, 1305-1308 (1998).

55. Wallach, D. et al. Tumor necrosis factor receptor and Fas signaling mechanisms. Annu. Rev. Immunol. 17, 331-367 (1999).

56. Henkler, F. et al. Caspase-mediated cleavage converts the tumor necrosis factor (TNF) receptor-associated factor (TRAF)-1 from a selective modulator of TNF receptor signaling to a general inhibitor of NF-kappa B activation. J. Biol. Chem. 278, 29216-29230 (2003).

57. Bishop, D. L., Misgeld, T., Walsh, M. K., Gan, W. B. \& Lichtman, J. W. Axon branch removal at developing synapses by axosome shedding. Neuron 44, 651-661 (2004).

58. Je, H. S. et al. Role of pro-brain-derived neurotrophic factor (proBDNF) to mature BDNF conversion in activity-dependent competition at developing neuromuscular synapses. Proc. Natl Acad. Sci. USA 109 15924-15929 (2012).

59. Popa, C., Netea, M. G., van Riel, P. L., van der Meer, J. W. \& Stalenhoef, A. F. The role of TNF-alpha in chronic inflammatory conditions, intermediary metabolism, and cardiovascular risk. J. Lipid Res. 48, 751-762 (2007).

60. Lee, Y. I. et al. Neuregulin1 displayed on motor axons regulates terminal Schwann cell-mediated synapse elimination at developing neuromuscular junctions. Proc. Natl Acad. Sci. USA 113, E479-E487 (2016).

61. Stevens, B. et al. The classical complement cascade mediates CNS synapse elimination. Cell 131, 1164-1178 (2007).

62. Datwani, $\mathrm{A}$. et al. Classical $\mathrm{MHCl}$ molecules regulate retinogeniculate refinement and limit ocular dominance plasticity. Neuron 64, 463-470 (2009).

63. Stephan, A. H., Barres, B. A. \& Stevens, B. The complement system: an unexpected role in synaptic pruning during development and disease. Annu. Rev. Neurosci. 35, 369-389 (2012).

64. Lee, H. et al. Synapse elimination and learning rules co-regulated by MHC class I H2-Db. Nature 509, 195-200 (2014).

65. Personius, K. E., Slusher, B. S. \& Udin, S. B. Neuromuscular NMDA receptors modulate developmental synapse elimination. J. Neurosci. 36, 8783-8789 (2016).

66. Wajant, H. \& Siegmund, D. TNFR1 and TNFR2 in the control of the life and death balance of macrophages. Front Cell Dev. Biol. 7, 91 (2019).

67. Erturk, A., Wang, Y. \& Sheng, M. Local pruning of dendrites and spines by caspase-3-dependent and proteasome-limited mechanisms. J. Neurosci. 34, 1672-1688 (2014).

68. Wang, J. Y. et al. Caspase-3 cleavage of dishevelled induces elimination of postsynaptic structures. Dev. Cell 28, 670-684 (2014).

69. Lee, R. H. et al. Neurodevelopmental effects of chronic exposure to elevated levels of pro-inflammatory cytokines in a developing visual system. Neural Dev 5, 2, https://doi.org/10.1186/1749-8104-5-2 (2010).

70. Brennan, K. J. \& Hardeman, E. C. Quantitative analysis of the human alpha-skeletal actin gene in transgenic mice. J. Biol. Chem. 268, 719-725 (1993).

71. Miniou, P. et al. Gene targeting restricted to mouse striated muscle lineage. Nucleic Acids Res. 27, e27 (1999).

72. Luo, Z. G. et al. Implication of geranylgeranyltransferase I in synapse formation. Neuron 40, 703-717 (2003).

73. He, M. et al. Autophagy induction stabilizes microtubules and promotes axon regeneration after spinal cord injury. Proc. Natl Acad. Sci. USA 113, 11324-11329 (2016).

74. Misgeld, T., Kummer, T. T., Lichtman, J. W. \& Sanes, J. R. Agrin promotes synaptic differentiation by counteracting an inhibitory effect of neurotransmitter. Proc. Natl Acad. Sci. USA 102, 11088-11093 (2005).

75. Leach, M. K. et al. The culture of primary motor and sensory neurons in defined media on electrospun poly-L-lactide nanofiber scaffolds. J. Vis. Exp. pii: 2389 (2011).

76. Wright, M. C., Cho, W. J. \& Son, Y. J. Distinct patterns of motor nerve terminal sprouting induced by ciliary neurotrophic factor vs. botulinum toxin. J. Comp. Neurol. 504, 1-16 (2007). 